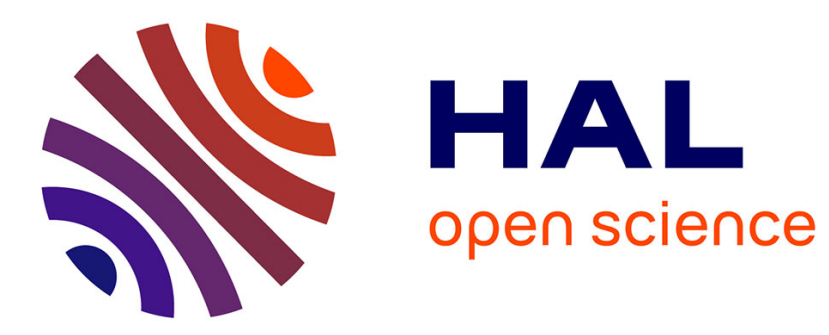

\title{
Genetic variation within and between populations of a desert poplar (Populus euphratica) revealed by SSR markers
}

\author{
Wang, Li, Guo, Ren, Wu
}

\section{To cite this version:}

Wang, Li, Guo, Ren, Wu. Genetic variation within and between populations of a desert poplar (Populus euphratica) revealed by SSR markers. Annals of Forest Science, 2011, 68 (6), pp.1143-1149. 10.1007/s13595-011-0119-6 . hal-00930688

\section{HAL Id: hal-00930688 https://hal.science/hal-00930688}

Submitted on 1 Jan 2011

HAL is a multi-disciplinary open access archive for the deposit and dissemination of scientific research documents, whether they are published or not. The documents may come from teaching and research institutions in France or abroad, or from public or private research centers.
L'archive ouverte pluridisciplinaire HAL, est destinée au dépôt et à la diffusion de documents scientifiques de niveau recherche, publiés ou non, émanant des établissements d'enseignement et de recherche français ou étrangers, des laboratoires publics ou privés. 


\title{
Genetic variation within and between populations of a desert poplar (Populus euphratica) revealed by SSR markers
}

\author{
Juan Wang • Zhijun Li • Qiuhong Guo • \\ Guangpeng Ren • Yuxia Wu
}

Received: 6 November 2010 / Accepted: 27 May 2011 /Published online: 25 August 2011

(C) INRA and Springer Science+Business Media B.V. 2011

\begin{abstract}
- Backgroud Populus euphratica Oliv., a long-lived woody perennial plant, is the only forest species naturally distributed in desert regions. Severe desertification has resulted in this species becoming endangered, and its populations are seriously fragmented in northwest China.

- Objectives We investigated the within-population and long-distance separated population diversity in northwest China using eight pairs of simple sequence repeat markers.

- Results Our results reveal that this species has high overall genetic diversity with a mean of 12.125 alleles per locus; its expected heterozygosity $\left(H_{\mathrm{e}}\right)$ ranged from 0.713 to 0.878 . However, there was a high level of genetic diversity within the species (when compared within congeneric species) and low genetic differentiation between populations (average $F_{\mathrm{st}}=0.093$ ). Analyses of molecular variance suggested that $5.21 \%$ of the total molecular variance was attributable to between-population diversity $(P<0.001)$, while the remainder of the variance was associated with differences within populations. There was no distinct correlation between geographical distributions and genetic variation.

- Conclusions We found no evidence to support our initial hypothesis of low genetic diversity within the species and
\end{abstract}

Handling Editor: Luc Pâques

Juan Wang and Zhijun Li contributed equally to this work.

J. Wang $\cdot$ Q. Guo $\cdot$ G. Ren $\cdot$ Y. Wu $(\bowtie)$

Molecular Ecology Group, Key Laboratory of Arid and Grassland

Ecology, Lanzhou University,

Lanzhou 730000, China

e-mail:wuyx@1zu.edu.cn

Z. Li

Life School of Plant Science, Talimu University,

Alaer 843300, China high differentiation between populations separated by long distances. The recent fragmentations of this species due to anthropologic and environmental effects resulted in its endangered status.

Keywords Populus euphratica . Simple sequence repeat (SSR) - Genetic diversity - Genetic differentiation

\section{Introduction}

The maintenance of genetic variation provides the potential for tree species to adapt to long-term environmental change (Hedrick 2004). Genetic diversity is also of importance in enabling a population to survive and reproduce under changing environmental conditions. A decrease in genetic variation has been correlated with a reduced adaptive flexibility, which threatens the ability of a species to survive via natural regeneration and has deleterious effects on species fitness. Therefore, assessments of the level and distribution of genetic diversity are important factors informing the management and development of effective conservation strategies for tree species. Most tree species exhibit a high level of genetic variation and a low level of between-population differentiation because they usually have widespread and continuous distributions and outcrossing breeding systems (Petit et al. 2004). However, for those trees species with fragmented distributions, intraspecific diversity tends to be relatively low and the genetic differentiation between populations is very high (Meng et al. 2007).

From an ecological and economic perspective, Populus euphratica is one of the most important poplar species in northwest China and is well known for its phreatophytic habit of growing in deserts (Bruelheide et al. 1999). P. euphratica is the main species responsible for afforestation 
of saline soil in sandy desert regions in northwest China and occurs at a few sites separated by a distance of 2 , $000 \mathrm{~km}$ east to west and $130 \mathrm{~km}$ north to south (Wang et al. 1995). The number of populations and individuals of this species has dropped considerably in recent years to the point where it is now considered to be endangered (Bruelheide et al. 1999). Such limited distribution and the long distances between isolated populations is typically indicative of a low genetic diversity within species and a high between-population differentiation. These characteristic features were observed in part by Saito et al. (2002) based on results from random amplified polymorphic DNA markers (RAPDs) during a study of populations from northern Xinjiang, which are genetically isolated from other populations in southern Xinjiang. One limitation of this study in establishing the level of diversity was the limited distribution of the five populations sampled as these were all collected around the Tianshan mountain range region of Xinjiang. Other representative populations of $P$. euphratica in northwest China (for example, in Gansu and Mongolia) were not included in the study. Although the RAPD technique can be a valuable tool for obtaining overall estimates of the genetic diversity of a species, it also has limitations, such as poor reproducibility and dominance of molecular markers. In contrast, simple sequence repeats (SSRs) provide more information because they are hypervariable and because of their co-dominance based on the presence of tandem repeated units of nucleotides that are ubiquitous in both protein coding and non-coding regions and are abundant in prokaryotic and eukaryotic genomes. Their uses have included studies of population and conservation genetics, the construction of genetic maps, parenthood analyses (van de Ven and McNicol 1996; Lexer et al. 2010), the assessment of genetic effects of forest management practice, and the development of strategies for conservation and sustainable management of forest genetic resources (Rajora et al. 2000; Rathmacher et al. 2010).
In this study, we investigate genetic variations within and between 10 populations of $P$. euphratica separated by long distances across northwest China using eight SSR loci (Wu et al. 2008). The two specific aims of this study were: (1) to assess genetic variation within and between populations and (2) to test the hypothesis that the distribution fragmentation has led to a decrease in genetic diversity and an increase in between-population differentiation.

\section{Materials and methods}

\subsection{Plant species and sampled populations}

We sampled 10 populations separated by long distances in northwest China. The seeds of P. euphratica are dispersed by both water and wind, and usually travel more than $200 \mathrm{~m}$. We chose 10-30 adult trees (with diameters at breast height at least $0.5 \mathrm{~m}$ ) spaced at least $200 \mathrm{~m}$ apart in each isolated forest stand. Two to three clean leaves were dried and stored in silica gel prior to DNA extraction. Thus, a total of 170 samples were used for DNA analysis, representing populations distributed across the northwest of China (Table 1). Latitude, longitude, and altitude were recorded for each collection site using an Etrex GIS unit (Garmin, Taiwan).

2.2 DNA extraction, PCR amplification, and polyacrylamide gel electrophoresis

Total DNA was extracted from the silica gel-dried leaves using the modified $2 \times$ CTAB procedure (Doyle and Doyle 1987). Eight SSR markers (Wu et al. 2008) were selected on the basis of their ability to amplify the DNA of all of the plants and the reproducibility of the products. The loci were located on the different genome regions according to the preliminary comparison to the available poplar genome (Tuskan et al. 2006). The SSR reactions were based on the
Table 1 The $P$. euphratica populations surveyed and their geographical parameters

$N$ number of sampled individuals

\begin{tabular}{|c|c|c|c|c|c|}
\hline Population & Location & $N$ & Latitude & Longitude & Altitude (m) \\
\hline Pop1 & Minqin, Gansu & 10 & $38^{\circ} 35^{\prime} 044^{\prime \prime}$ & $102^{\circ} 58^{\prime} 585^{\prime \prime}$ & 1,367 \\
\hline Pop2 & Ejinaqi, Neimenggu & 10 & $42^{\circ} 02^{\prime} 000^{\prime \prime}$ & $101^{\circ} 14^{\prime} 000^{\prime \prime}$ & 920 \\
\hline Pop3 & Ejinaqi, Neimenggu & 10 & $42^{\circ} 02^{\prime} 000^{\prime \prime}$ & $101^{\circ} 03^{\prime} 00^{\prime \prime}$ & 920 \\
\hline Pop4 & Kelamayi, Xinjiang & 10 & $46^{\circ} 08^{\prime} 11^{\prime \prime}$ & $85^{\circ} 38^{\prime} 829^{\prime \prime}$ & 302 \\
\hline Pop5 & Shawan, Xinjiang & 10 & $44^{\circ} 50^{\prime} 46^{\prime \prime}$ & $85^{\circ} 29^{\prime} 278^{\prime \prime}$ & 308 \\
\hline Pop6 & Luntai, Xingjiang & 30 & $41^{\circ} 15^{\prime} 15.4^{\prime \prime}$ & $84^{\circ} 12^{\prime} 18.6^{\prime \prime}$ & 918 \\
\hline Pop7 & Ruoqiang, Xinjiang & 20 & $39^{\circ} 44^{\prime} 48.0^{\prime \prime}$ & $88^{\circ} 24^{\prime} 01.3^{\prime \prime}$ & 802 \\
\hline Pop8 & Minfeng, Xinjiang & 20 & $37^{\circ} 11^{\prime} 56.8^{\prime \prime}$ & $82^{\circ} 47^{\prime} 55.6^{\prime \prime}$ & 1,360 \\
\hline Pop9 & Moyu, Xinjiang & 20 & $37^{\circ} 34^{\prime} 43.9^{\prime \prime}$ & $79^{\circ} 38^{\prime} 10.4^{\prime \prime}$ & 1,280 \\
\hline Pop10 & Maigaiti, Xinjiang & 30 & $39^{\circ} 21^{\prime} 40.4^{\prime \prime}$ & $78^{\circ} 05^{\prime} 30.7^{\prime \prime}$ & 1,140 \\
\hline
\end{tabular}


protocol of $\mathrm{Wu}$ et al. (2008), with some modifications. Amplification reactions were performed in a volume of $20 \mu \mathrm{l}$ containing $1 \times$ reaction buffer (Takara), 8-12 ng genomic DNA, $200 \mu \mathrm{M}$ of each dNTP, $16 \mu \mathrm{M}$ of each primer, and $1 \mathrm{U}$ of Taq DNA polymerase (Takara). The Cycler $^{\mathrm{TM}}$ Thermal Cycler (Bio-Rad, USA) PCR was programmed according to the following profile: $94^{\circ} \mathrm{C}$ for $7 \mathrm{~min} ; 94^{\circ} \mathrm{C}$ for $40 \mathrm{~s}, 50-58^{\circ} \mathrm{C}$ for $30 \mathrm{~s}, 72^{\circ} \mathrm{C}$ for $30 \mathrm{~s}, 37$ cycles; and $72^{\circ} \mathrm{C}$ for $7 \mathrm{~min}$. After PCR amplification, $2 \mu \mathrm{l}$ of each sample was loaded and electrophoresed on a $2 \%$ horizontal agarose gel to check for positive amplification and to determine the approximate amount of the product. The remaining PCR products were separated on $6.5 \%(w / v)$ polyacrylamide denaturing gel and visualized by silver staining. The band size was monitored using a 10-bp DNA ladder (Tiangen) as the reference. In order to reduce errors, we maintain all experiments for the same condition.

\subsection{Summary statistics}

For each locus, genotypes exhibiting one or two bands were scored as being homozygous or heterozygous, respectively. We did not detect null alleles in the sampled loci. We measured intra- and inter-population genetic statistics using the program GENEPOP 3.4 (Raymond and Rousset 1995), including the expected heterozygosity $\left(H_{\mathrm{e}}\right)$, observed heterozygosity $\left(H_{\mathrm{o}}\right)$, and the effective number of alleles $\left(N_{\mathrm{e}}\right)$. We also calculated Shannon's indices $\left(H_{\mathrm{pop}}\right)$ to characterize genetic variation within and between populations.

We further calculated the pairwise standard genetic distance (Nei 1972), and an unrooted tree was constructed using a least squares algorithm with 10,000 bootstraps over the microsatellite loci, implemented in the PHYLIP v. 3.6c software package (Felsenstein 1993). We determined the genetic relationship between populations with the STRUCTURE program using the admixture model (Pritchard et al. 2000). This model assumes that the genome of an individual is a mixture of genes originating from $K$ unknown "ancestral" populations that may have undergone introgression events (the unknown $K$ ancestral populations were assumed to have been at HW equilibrium). Eighteen independent runs were performed for each $K$ value, from $K=1$ to $K=10$. The range of $K$ values was set to include the total number of populations $(K=10)$. Each run consisted of a burn-in period of 100,000 steps, followed by $10^{6} \mathrm{MCMC}$ (Monte Carlo Markov chain) replicates. The choice of the appropriate $K$ value was based on the recommendations of Pritchard et al. (2000). The runs with the highest $\ln \operatorname{Pr}(X \mid K)$ values were selected and the proportion of ancestry of each population in each of the clusters was calculated by averaging the estimated membership coefficient of the combined individuals and ancestry estimate. For individuals, the admixture level was analyzed by assigning the individual to a cluster if an arbitrary value of $75 \%$ of its genome appeared to belong to that cluster (Matsuoka et al. 2002), while those individuals with membership probabilities of $<75 \%$ for all clusters were considered to be of "mixed origin." In order to test for a correlation between Nei's genetic distance and geographic distance (in meters) between populations, a Mantel test was performed using TFPGA (Miller 1997) for population genetic analysis (999 permutations were calculated). We also derived approximations of the genetic structures using Wright's analysis of hierarchical $F$ statistics (Wright 1978). Gene flow $\left(N_{\mathrm{m}}\right)$ was estimated using the equation $N_{\mathrm{m}}=0.25\left(1-F_{\mathrm{st}}\right) / F_{\mathrm{st}}$. To estimate the variance component and to partition the variation within and between populations, we used analysis of molecular variance (AMOVA) implemented in the ARLEQUIN program (Schneider et al. 2000).

\section{Results}

\subsection{Microsatellite polymorphisms}

The total number of alleles per locus and the size range of the alleles detected in P. euphratica are given in Table 2. A total of 97 alleles were detected at eight SSR loci within the 10 sampled populations. The number of alleles per locus ranged from 8 to 16 , with a mean value of 12.125 . Genetic diversity parameters per locus indicated a high number of polymorphisms, which are listed in Table 2 . The total $H_{\mathrm{o}}$ ranged from 0.761 to 1.000 . The average expected $H_{\mathrm{e}}$ was slightly lower than the $H_{\mathrm{o}}$, ranging from 0.713 to 0.878 . The observed number of alleles per locus $\left(N_{\mathrm{a}}\right)$ ranged from 8 to 13 , with an average of 11 , while the effective number of alleles per locus $\left(N_{\mathrm{e}}\right)$ ranged from 3.45 to 8.00 , with an average of 6.56. The maximum value of $H_{\mathrm{o}}$ was found in Pop3 and the minimum in Pop9 (Table 3). $H_{\mathrm{e}}$ varied from 0.720 (Pop5) to 0.831 (Pop10). Shannon's information index $\left(H_{\mathrm{pop}}\right)$ ranged from 1.300 (Pop6) to 1.857 (Pop2), with an average of 1.631 alleles (Table 3 ).

\subsection{Genetic differentiation between populations}

To estimate genetic differentiation between populations, the fixation index $F_{\text {st }}$, originally formulated by Wright (1978), was utilized using the program POPGENE 3.4 (Raymond and Rousset 1995), in which modifications were made to avoid errors arising from the small sample size and to enable analyses of multi-alleles at multi-loci. The $F_{\text {st }}$ values ranged from 0.025 to 0.162 , with an average value of 0.093 . The overall gene flow $\left(N_{\mathrm{m}}\right)$ between populations was estimated to be 2.446 , which provided an estimate of the average number of migrants between all studied populations per generation (Table 4). 
Table 2 Relative measures of genetic differentiation and estimates of gene flow among populations of P. euphratica

\begin{tabular}{|c|c|c|c|c|c|c|c|c|c|c|}
\hline Locus & Repeat motif & Size range $(b p)$ & $N_{\mathrm{a}}$ & $N_{\mathrm{e}}$ & $H_{\mathrm{o}}$ & $H_{\mathrm{e}}$ & $F_{\text {is }}$ & $F_{\text {it }}$ & $F_{\text {st }}$ & $N_{\mathrm{m}}$ \\
\hline $\mathrm{Pe} 2$ & $(\mathrm{CT})_{9}-(\mathrm{CA})_{11}$ & $249-281$ & 9.00 & 5.84 & 1.000 & 0.831 & -0.295 & -0.205 & 0.069 & 3.368 \\
\hline $\mathrm{Pe} 4$ & $(\mathrm{TC})_{11}$ & $190-235$ & 8.00 & 3.45 & 0.988 & 0.713 & -0.410 & -0.375 & 0.025 & 9.806 \\
\hline Pe5 & $(\mathrm{TC})_{14}$ & $168-218$ & 13.00 & 8.00 & 0.899 & 0.878 & -0.193 & -0.001 & 0.162 & 1.298 \\
\hline Pe6 & $(\mathrm{TG})_{16}$ & 164-206 & 11.00 & 6.77 & 0.982 & 0.855 & -0.240 & -0.155 & 0.069 & 3.398 \\
\hline $\mathrm{Pe} 7$ & $(\mathrm{TG})_{10}$ & $92-110$ & 12.00 & 7.56 & 1.000 & 0.870 & \multirow{2}{*}{\multicolumn{2}{|c|}{$0.003^{-0.311} 0.083$}} & 0.119 & 1.847 \\
\hline $\mathrm{Pe} 8$ & $(\mathrm{TG})_{12-}(\mathrm{GA})_{11}$ & $146-199$ & 13.00 & 7.16 & 0.761 & 0.863 & & & 0.080 & 2.859 \\
\hline Pe14 & $(\mathrm{GT})_{26}$ & $175-233$ & 12.00 & 7.98 & 0.814 & 0.877 & \multicolumn{2}{|c|}{$-0.085 \quad 0.056$} & 0.130 & 1.674 \\
\hline Pe16 & $(\mathrm{AC})_{17}$ & $128-147$ & 10.00 & 5.74 & 1.000 & 0.828 & -0.314 & -0.219 & 0.073 & 3.191 \\
\hline Mean & & & 11.00 & 6.56 & 0.932 & 0.839 & -0.228 & -0.114 & 0.093 & 2.446 \\
\hline
\end{tabular}

$F_{\text {is }}$ within-population coefficient of inbreeding, $N_{\mathrm{m}}$ gene flow estimated from $N_{\mathrm{m}}=0.25\left(1-F_{\mathrm{st}}\right) / F_{\mathrm{st}}, N_{\mathrm{e}}$ effective number of alleles, $N_{\mathrm{a}}$ observed number of alleles

Long-distance isolation usually results in an increase in genetic differentiation. In order to identify any geographical correlation between the recovered gene pools or genetic groups and sampled populations, we performed a Mantel test with 1,000 permutations. We detected a non-significant correlation between genetic distance and geographic distance $(r=0.3217, p=0.058>0.05$; Fig. 1$)$. The most probable division of populations was when $K=4$; this received the highest support in terms of log-likelihood values, as suggested by Pritchard et al. (2000). The four clustered groups of populations showed no correspondence to geographic location (Fig. 2), nor was there any geographical pattern within the clustered populations. We used AMOVA to examine further the genetic differentiation within and between populations. We conducted two types of group estimate: (1) four genetic groups identified by genetic distances and using STRUCTURE 2.3.2 and (2) two geographical regions isolated by deserts (Xinjiang versus Gansu and Inner Mongolia), with a long distance between them (Fig. 1). AMOVA analyses indicated that $5.21 \%$ of the total molecular variance was attributable to between-population diversity $(P<0.001)$, while the remainder
$(94.79 \%)$ was associated with differences within populations (Table 5).

\section{Discussion}

In this study, SSR markers were used to estimate the level of genetic diversity, an approach that has been shown to be appropriate in many studies (van de Ven and McNicol 1996; Dayanandan et al. 1998; Rajora et al. 2000; Fossati et al. 2003; Rathmacher et al. 2010). In the present study, we examined the genetic variations of the only eight SSR loci and used the polyacrylamide denaturing gel and silver staining to check genetic polymorphisms at each locus. We sampled only 10 individuals for a few populations. The genetic diversity within species and population level will increase with the sampled individuals and populations (e.g., Dayanandan et al. 1998). In addition, our experimental approach may neglect the SSR polymorphisms caused by the small repeats at the same locus between different individuals when the resultant migrating differences are too low. These limitations may underestimate the genetic
Table 3 Genetic variation within populations of $P$. euphratica based on eight SSR loci

$N_{\text {at }}$ total number of alleles per population, $N_{\mathrm{r}}$ number of rare alleles (alleles present in fewer than $5 \%$ of the individuals) per population, $N_{\mathrm{a}}$ observed number of alleles, $N_{\mathrm{e}}$ effective number of alleles per population, $H_{\mathrm{o}}$ observed heterozygosity, $H_{\mathrm{e}}$ expected heterozygosity, $H_{\text {pop }}$ Shannon's information index

\begin{tabular}{llllllll}
\hline Population & $N_{\text {at }}$ & $N_{\mathrm{r}}$ & $N_{\mathrm{a}}$ & $N_{\mathrm{e}}$ & $H_{\mathrm{o}}$ & $H_{\mathrm{e}}$ & $H_{\text {pop }}$ \\
\hline Pop1 & 11 & 1 & 5.750 & 3.998 & 0.888 & 0.753 & 1.474 \\
Pop2 & 12 & 2 & 5.125 & 3.700 & 0.950 & 0.761 & 1.418 \\
Pop3 & 11 & 0 & 5.375 & 4.218 & 1.000 & 0.792 & 1.515 \\
Pop4 & 10 & 0 & 5.250 & 4.142 & 0.988 & 0.749 & 1.415 \\
Pop5 & 12 & 1 & 4.625 & 3.379 & 0.925 & 0.720 & 1.300 \\
Pop6 & 12 & 0 & 8.000 & 5.304 & 0.966 & 0.808 & 1.765 \\
Pop7 & 11 & 0 & 7.625 & 5.601 & 0.908 & 0.834 & 1.816 \\
Pop8 & 12 & 0 & 8.000 & 4.916 & 0.863 & 0.803 & 1.752 \\
Pop9 & 13 & 1 & 8.375 & 5.152 & 0.850 & 0.819 & 1.817 \\
Pop10 & 13 & 0 & 8.375 & 5.819 & 0.978 & 0.831 & 1.857 \\
Mean & 11.7 & 0.5 & 6.65 & 4.623 & 0.932 & 0.787 & 1.613 \\
\hline
\end{tabular}


Table 4 Proportion of ancestry of each population in each of three $P$. euphratica clusters defined using the model-based clustering method of Pritchard et al. (2000)

\begin{tabular}{|c|c|c|c|c|c|c|c|c|c|}
\hline \multirow[t]{2}{*}{ Population } & \multicolumn{2}{|l|}{$K=2$} & \multicolumn{3}{|l|}{$K=3$} & \multicolumn{4}{|l|}{$K=4$} \\
\hline & A & B & A & B1 & B2 & A1 & A2 & B1 & B2 \\
\hline Pop1 & 0.200 & 0.800 & 0.325 & 0.059 & 0.617 & 0.196 & 0.032 & 0.101 & 0.671 \\
\hline Pop2 & 0.407 & 0.593 & 0.058 & 0.101 & 0.841 & 0.805 & 0.043 & 0.036 & 0.116 \\
\hline Pop3 & 0.501 & 0.499 & 0.794 & 0.126 & 0.080 & 0.056 & 0.071 & 0.114 & 0.758 \\
\hline Pop4 & 0.628 & 0.372 & 0.225 & 0.580 & 0.195 & 0.206 & 0.480 & 0.234 & 0.080 \\
\hline Pop5 & 0.102 & 0.898 & 0.038 & 0.047 & 0.915 & 0.908 & 0.027 & 0.033 & 0.032 \\
\hline Pop6 & 0.717 & 0.283 & 0.160 & 0.588 & 0.252 & 0.183 & 0.503 & 0.049 & 0.265 \\
\hline Pop7 & 0.572 & 0.428 & 0.225 & 0.498 & 0.278 & 0.209 & 0.438 & 0.139 & 0.213 \\
\hline Pop8 & 0.476 & 0.524 & 0.378 & 0.340 & 0.282 & 0.264 & 0.246 & 0.439 & 0.051 \\
\hline Pop9 & 0.298 & 0.702 & 0.580 & 0.201 & 0.218 & 0.162 & 0.124 & 0.600 & 0.114 \\
\hline Pop10 & 0.726 & 0.274 & 0.309 & 0.553 & 0.138 & 0.091 & 0.455 & 0.142 & 0.312 \\
\hline
\end{tabular}

polymorphisms of this species and the sampled populations, but will not affect the main aim of this study to examine the genetic differentiation between populations. Despite this, we still identified a high level of polymorphism within each population (Table 2) and the species across all loci (Table 3$)$. The observed heterozygosity $\left(H_{\mathrm{o}}=\right.$ 0.932) had significantly higher values than the expected heterozygosity $\left(H_{\mathrm{e}}=0.787\right.$; Tables 2 and 3$)$. All these estimates were much higher than the genetic diversity indexes for this species found using RAPD markers (Saito et al. 2002). Similar values were also reported for congeneric Populus nigra with SSR markers $\left(H_{\mathrm{o}}=0.70\right.$, $H_{\mathrm{e}}=0.73$; Rathmacher et al. 2010). However, lower levels of polymorphism have been reported for two other poplar species: Populus alba $\left(H_{\mathrm{o}}=0.341, H_{\mathrm{e}}=0.368\right)$ and Populus tremula $\left(H_{\mathrm{o}}=0.483, H_{\mathrm{e}}=0.492\right.$; Lexer et al. 2005).

The desert poplar studied here is found in northwest China, and the sampled populations were separated by long distances. However, we did not detect high population

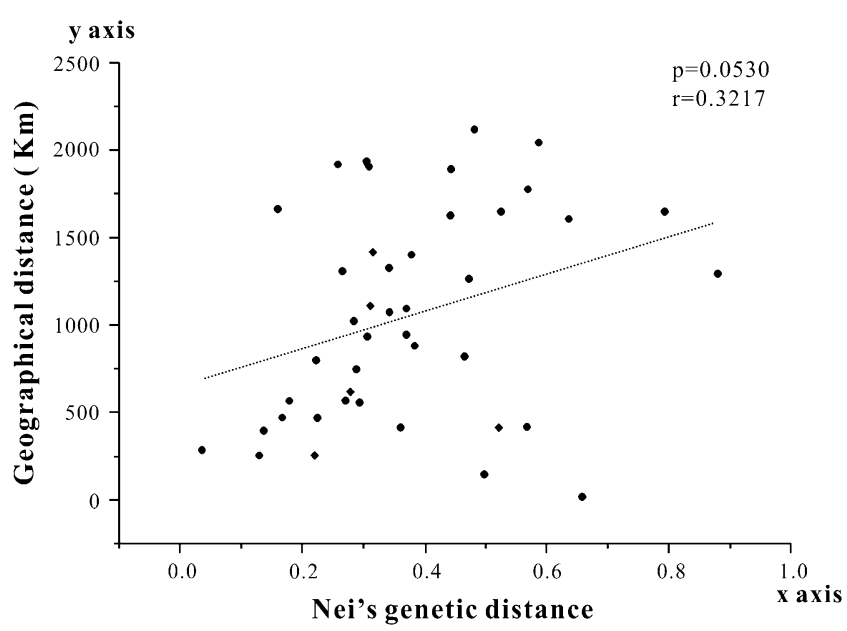

Fig. 1 Correlation between geographic distance and Nei's genetic distance revealed by the Mantel test ( $p>0.05$; TFPGA; Miller 1997) differentiation $\left(F_{\mathrm{st}}=0.093\right)$. The low level of differentiation was also confirmed by the AMOVA, which indicated that only $5.21 \%$ of the total molecular variance was attributable to between-population diversity (Table 5). The STRUCTURE 2.3.2 analyses and Mantel test also indicated that the sampled populations showed no corresponding geographical groupings and that the genetic variations were not correlated with the geographic isolation (Fig. 1 and Table 4). The low differentiation detected in the species is similar to that reported for congeneric species based on the SSR marking. For example, mean $G_{\mathrm{ST}}$ values of only 0.15 and 0.017 have been reported for $P$. nigra and $P$. tremula, respectively, based on SSR analyses (Fossati et al. 2003; Lexer et al. 2005). These estimates are similar to estimates of corresponding parameters for wide-ranging species including Lychnis flos-cuculi L. $\left(F_{\mathrm{st}}=0.022\right)$ and Phlebia centrifuga $\left(F_{\mathrm{st}}=\right.$ 0.061; Galeuchet et al. 2005; Franzen et al. 2007).

Our genetic analyses indicate that the $P$. euphratica populations are characterized by a high level of genetic diversity and low population differentiation (Tables 2 and 3). Three possible factors may account for such a genetic pattern. First, P. euphratica is dioecious and is an outcrossing species. Its pollen is dispersed by the wind over long distances, and this is likely to promote gene flow between isolated populations. This is undoubtedly likely to enhance intraspecific diversity and reduce inter-population differentiation (Hedrick 2004). Secondly, the majority of individuals of this species are long-lived (a life span of $>200$ years has been estimated) and have extensive clonal growth (Wiehle et al. 2009). The current stands in most populations are, therefore, likely to be well established for a long time through cloning reproductions while these daughter ramets maintained the same genetic diversity as their parents (Vonlanthen et al. 2010). Thirdly, the long isolation between the sampled populations may have occurred recently because of human disturbance and 
Fig. 2 a The tree based on pairwise standard genetic distances (Nei 1972) was constructed using the PHYLIP v. 3.6c software package. b Bar plots showing the proportion of inferred co-ancestry based on Bayesian clustering analysis. A population assignment test using STRUCTURE (version 2.3.2) software based on eight microsatellite loci produced from different groups $(K=4)$ a
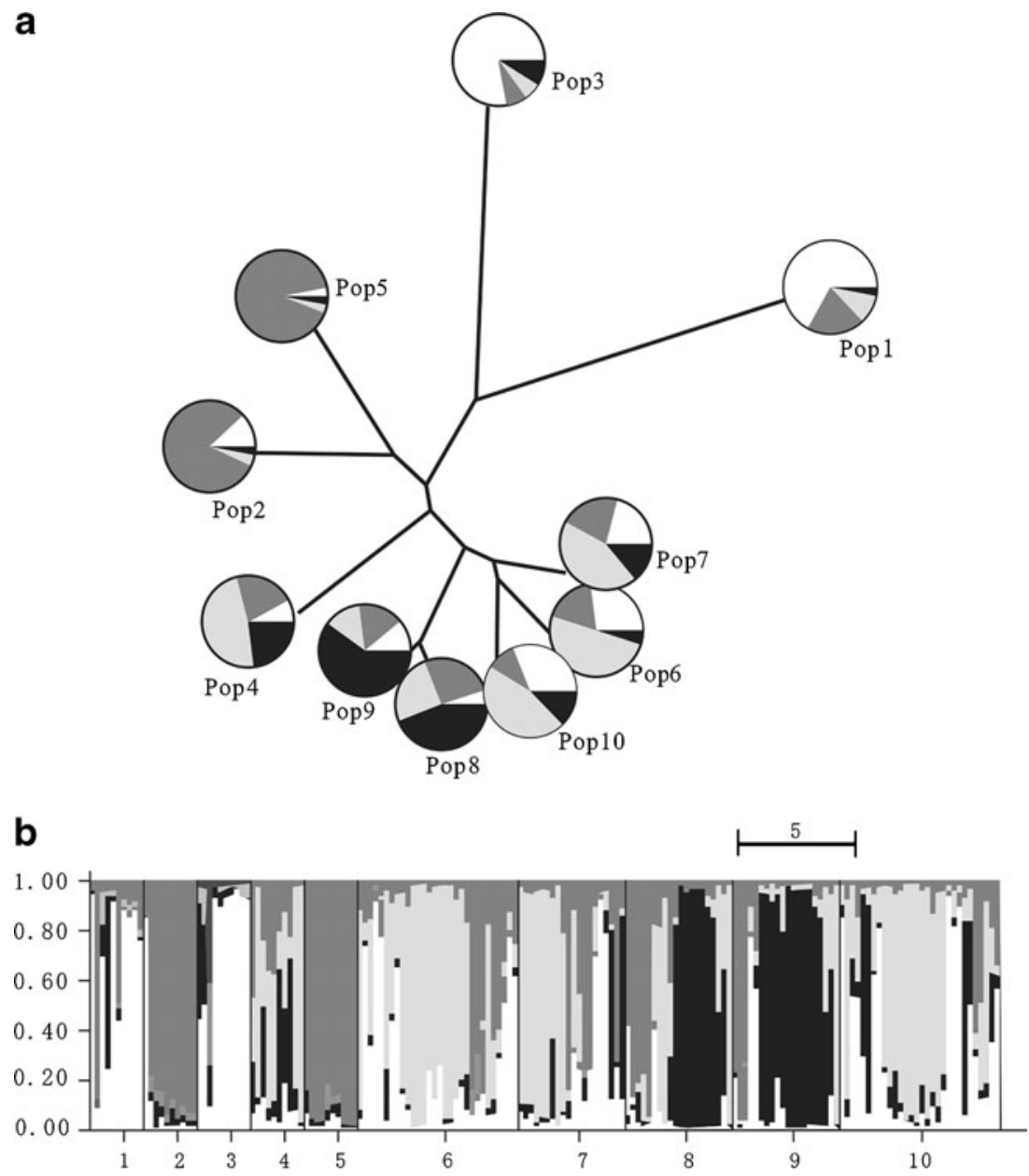

climatic changes. For example, most forests composed of this species were cleared for agricultural purposes during the period from 1950 to 1960 (Chen et al. 2006). In addition, during the past 100 years, precipitation in the northwest has declined dramatically and most rivers have dried up (Zhang et al. 2003). The shortage of water and expansion of the desert resulted in the death of poplars at a number of sites. However, at the other sites, a few populations persist due to the availability of waters in the microhabitats. The long life cycle and clonal reproduction of this species may have helped these current fragmented populations to retain their historical genetic diversity when these populations were connected. Therefore, it is imaginable that the fragmentations are too short to cause the genetic differentiations between populations. Overall, our findings suggest that the endangered status of the species is
Table 5 Results of the AMOVA test of the P. euphratica population genetic structure

$d f$ degrees of freedom, SSD sum of squares

\begin{tabular}{lrrccc}
\hline Source of variation & $d f$ & \multicolumn{1}{l}{ SSD } & Variance component & Total variance (\%) & Fixation index \\
\hline $\begin{array}{l}\text { Total populations } \\
\text { Between populations }\end{array}$ & 9 & 77.990 & 0.1684 & 5.21 & \\
$\begin{array}{l}\text { Within populations } \\
\text { Two groups }\end{array}$ & 330 & $1,011.017$ & 3.0637 & 94.79 & $F_{\text {st }}=0.052$ \\
Between groups & 1 & 9.568 & 0.0130 & & \\
Between populations & 8 & 68.321 & 0.1622 & 0.40 & $F_{\mathrm{ct}}=0.004$ \\
Within populations & 330 & $1,011.017$ & 3.0637 & 5.01 & $F_{\mathrm{sc}}=0.050$ \\
Four groups & & & & 94.59 & $F_{\mathrm{st}}=0.054$ \\
Between groups & 1 & 13.408 & 0.1116 & 3.41 & $F_{\mathrm{ct}}=0.034$ \\
Between populations & 4 & 27.819 & 0.1047 & 3.20 & $F_{\mathrm{sc}}=0.033$ \\
Within populations & 214 & 654.242 & 3.0572 & 93.39 & $F_{\mathrm{st}}=0.066$ \\
\end{tabular}


mainly due to anthropologic and environmental effects rather than a lack of genetic diversity.

Acknowledgments Financial support for this research was provided by NSFC (30800865) and the Program for New Century Excellent Talents in the Ministry of Education in China (NCET-09-0446).

\section{References}

Bruelheide H, Jandt U, Gries D, Thomas FM, Foetzki A, Buerkert A, Gang W, Zhang XM, Bussell JD (1999) The distribution of random amplified polymorphic DNA (RAPD) diversity amongst populations of Isotoma petraea (Lobeliaceae). Mol Ecol 8:775789

Chen YN, Zilliacus H, Li WH, Zhang HF, Chen YP (2006) Ground-water level affects plant species diversity along the lower reaches of the Tarim River, Western China. J Arid Environ 66:231-246

Dayanandan SO, Rajora OP, Bawa KS (1998) Isolation and characterization of microsatellites in trembling aspen (Populus tremuloides). Theor Appl Genet 96:950-956

Doyle JJ, Doyle JL (1987) A rapid DNA isolation procedure from small quantities of fresh leaf tissues. Phyto Bull 19:11-15

Felsenstein J (1993) PHYLIP (Phylogeny Inference Package) version 3.5c. Department of Genetics, University of Washington, Seattle

Fossati T, Grassi F, Sala F, Castiglione S (2003) Molecular analysis of natural populations of Populus nigra L. intermingled with cultivated hybrids. Mol Ecol 12:2033-2043

Franzen I, Vasaitis R, Penttila R, Stenlid J (2007) Population genetics of the wood-decay fungus Phlebia centrifuga $\mathrm{P}$ Karst in fragmented and continuous habitats. Mol Ecol 16:3326-3333

Galeuchet DJ, Perret C, Fischer M (2005) Microsatellite variation and structure of 28 populations of the common wetland plant, Lychnis flos-cuculi L., in a fragmented landscape. Mol Ecol 14:991-1000

Hedrick PW (2004) Recent developments in conservation genetics. For Ecol Manag 197:3-19

Lexer C, Fay MF, Joseph A, Nica MS, Heinze B (2005) Barrier to gene flow between two ecologically divergent Populus species, $P$. alba (white poplar) and P. tremula (European aspen): the role of ecology and life history in gene introgression. Mol Ecol 14:1045-1057

Lexer C, Joseph JA, van Loo M, Barbara T, Heinze B, Bartha D, Castiglione S, Fay MF, Buerkle CA (2010) Genomic admixture analysis in European Populus spp. reveals unexpected patterns of reproductive isolation and mating. Genet 186:699-712

Matsuoka Y, Vigouroux Y, Goodman MM, Sanchez GJ, Buckler E, Doebley J (2002) A single domestication for maize shown by multilocus microsatellite genotyping. Proc Natl Acad Sci USA 99:6080-6084
Meng LH, Yang R, Abbott RJ, Miehe G, Hu TH, Liu JQ (2007) Mitochondrial and chloroplast phylogeography of Picea crassifolia Kom. (Pinaceae) in the Qinghai-Tibetan Plateau and adjacent highlands. Mol Ecol 16:4128-4137

Miller MP (1997) Tools for population genetic analysis. Version 1.3. Department of Biological Sciences, Northern Arizona University, Flagstaff

Nei M (1972) Genetic distance between populations. Am Nat 106:283-292

Petit RJ, Bialozyt R, Garnier-Gereand P, Hampe A (2004) Ecology and genetics of tree invasions: from recent introductions to Quaternary migrations. For Ecol Manag 197:117-137

Pritchard JK, Stephens M, Donnelly P (2000) Inference of population structure using multilocus genotype data. Genetics 155:945-959

Rajora OP, Rahman MH, Buchert GP, Dancik BP (2000) Microsatellite DNA analysis of genetic effects of harvesting in old-growth eastern white pine (Pinus strobes) Ontario, Canada. Mol Ecol 9:339-348

Rathmacher G, Niggemann M, Kohnen M, Ziegenhagen B, Bialozyt R (2010) Short-distance gene flow in Populus nigra L. accounts for small-scale spatial genetic structures: implications for in situ conservation measures. Conserv Genet 11:1327-1338

Raymond M, Rousset F (1995) GENEPOP (version 1.2): population genetics software for exact tests and ecumenicism. J Hered 86:248-249

Saito Y, Shiraishi S, Tanimoto T, Yin L, Watanabe S, Ide Y (2002) Genetic diversity of Populus euphratica populations in northwestern China determined by RAPD DNA analysis. New For 23:97-103

Schneider S, Roessli D, Excoffier L (2000) Arlequin ver. 2.0: a software for population genetic data analysis. Genetics and Biometry Laboratory, University of Geneva, Geneva

Tuskan GA, DiFazio S, Jansson S et al (2006) The genome of black cottonwood, Populus trichocarpa (Torr. \& Gray). Science 313:1596-1604

Van de Ven WTG, McNicol RJ (1996) Microsatellites as DNA markers in Sitka spruce. Theor Appl Genet 93:613-617

Vonlanthen B, Zhang XM, Bruelheide H (2010) Clonal structure and genetic diversity of three desert phreatophytes. Amer J Bot 97:234-242

Wang SJ, Chen BH, Li HQ (1995) Euphrates poplar forest. China Environmental Science Press, Beijing

Wiehle M, Eusemann P, Thevs N, Schnittler M (2009) Root suckering patterns in Populus euphratica (Euphrates poplar, Salicaceae). Trees 23:991-1001

Wright S (1978) Variability within and among natural populations. The University of Chicago Press, Chicago

Wu YX, Wang J, Liu JQ (2008) Development and characterization of microsatellite markers in Populus euphratica (Populaceae). Mol Ecol Res 8:1142-1144

Zhang H, Wu JW, Zheng QH, Yu YJ (2003) A preliminary study of oasis evolution in the Tarim Basin, Xinjiang, China. J Arid Envir $55: 545-553$ 